\title{
Social Criticism: From Utopia to Post-utopian Thought
}

\author{
Svetlana Rudanovskaya \\ Department of Social Philosophy \\ Faculty of Humanities and Social Sciences \\ Peoples' Friendship University of Russia \\ Moscow, Russia \\ E-mail: rudsv@live.ru
}

\begin{abstract}
The article deals with social criticism and its ideals that undergo transformation in the situation of mass media society (with its unification tendencies as well as pluralism in views and approaches to reality). Contemporary critics are characterized first of all by their sensitivity to language, its ideological power, complexity and possibilities for mutual understanding. On the one hand, contemporary critical discourse avoids utopian intentions of liberation from imperfect society; on the other hand, it uses post-utopian images of ideal talk to other people which is supposed to make some micro, but essential changes in their attitudes and relations.
\end{abstract}

Keywords-social criticism; interpretation; post-utopian thinking; critique of language; "ideal speech situation"; understanding

\section{INTRODUCTION}

Disagreement with the current nature of things, in particular with the well-ordered, established "disorder" unreasonable social environment, callous human relations, unfair distribution of knowledge, power and goods - has been a constant motive of social criticism throughout the course of history. But it is the human ability to adapt oneself to "bad" social conditions, follow the repetitive mode in the daily routine, perceiving the events with fatal despair, that arouses the most intense indignation among those who are engaged in the process of social reflection.

The everyday life with its predictability, absence of any transcendental search, closed nature of the outlook becomes a number one enemy for a social critic, led by the faith in the possible social improvement, validity of new ideas, projects, ideals. Social criticism, no matter what form it may take or how pessimistic it may estimates the actual state of society, is incompatible with fatalism. Fatalism implies the obedience to fate, while the basic imperative of social criticism is the struggle for accomplishment of human designs and aspirations.

Social criticism aims at enabling humans to pass from passive agreement with the present social conditions to active rejection of their status of "humiliated and insulted", deprived of due share by society, history, fate. The critique initiates a riot against an alien reality and at the same time against the idea that everything will take care of itself without any efforts being taken.

Attacking the inertia of social institutions, the most famous critics note the human inability to go beyond the immanent reality, distinguish between the real and the possible. The prophets revealing the absence of strong faith, automatic adherence to covenants, philosophers indignant about superstitions, "idols of consciousness", Marxist criticism of silent approval of human exploitation, alienated social relations, existential criticism of negligent attitude to one's own existence - all those approaches stresses the fact that people are alienated from themselves, (particularly from their need to change themselves), that most of them have forgotten how to strive for the best.

\section{SOCIAL CRITICISM AND UTOPIAN INTENTIONS}

Hope for the best accompanies all social projects, but it may release utopian imagination when coupled with the faith in literary fulfillment of "the best" despite the social context. At the level of utopian imagination a mental break with reality takes place, and this break serves as a starting point for imaginary construction of a new society, distinguished drastically from the old one.

Up to the middle of the 20th century social critics' interest had centered on the ideal of a New Man who thinks and feels otherwise and is characterized by the awareness of new opportunities, untouched resources, conventionality of social norms and codes of human behaviour. A New Man is driven more by a maximalist desire to eliminate the gap between what it is and what it should be, by commitment to realize the images of absolute agreement, everybody's freedom from sufferings, economic necessity and down-toearth logic of the common sense once and for all.

A New Man appealed to "big" problems of History and Progress, set large-scale goals of saving the humanity and society, overcame huge obstacles (the opposition of public opinion and the state). Being a revolutionist by nature, a New Man was depicted by his heroic determination to radically change a social order, a sphere of human relations, a general world view. A protest was his mode of existence, a conflict 
was a way of his relationship with authorities and public opinion.

Still this perfectionism justified by big goals and high ideals is fraught with a risk of violence since the effort to build another society makes human mind disregard this one which is not in accordance with ideal samples. Wishing the best may turn into the dictate of ideals, into the criticism stripped from mere human intentions: conversing with others, sharing with them either the subjective experience or one of the possible opportunities to improve the social order.

Throughout history, a critic who appeals to the idea of a New Man actually personified this idea. His word was always in the minority and had an explosive effect, undermining the trust in the established system of meanings. In the context of day-to-day life the protest of this person used to be the real event that stood for the possibility of a different way of thinking, a different way of life.

A social critic opposed his projects to the rigid, unchangeable postulates of the governing ideology, encouraging people to overcome visible and invisible restrictions of thought. A rigidity of criticism was compatible with hardness of opposed forces. A clear doubtless picture of social life with all its drawbacks was one of the necessary conditions for efficacy of the critical discourse and the practice of protesting. This situation starts transmuting under the influence of mass media, when numerous interpretations of events introduce information uncertainty as well as "anything goes" attitude among mass audience.

\section{THE OBJECT OF CRITICAL INTERPRETATION: LANGUAGE OF CULTURE}

The object of social criticism is born from an experience of distrust in the language of culture, the desire to call things by their proper names. Criticism concerns with renaming things, liberating them from the habitual positivity, while destructing the state of human reconciliation with reality. In modern society renaming things, on the one hand, poses no problems as lots of experts, politicians, writers and commentators produce different interpretations of events, a multiple versions of readings and understanding. The information environment is open to new statements condemnatory, affirmative, revelatory. On the other hand, renaming things is getting more and more complicated for it excludes any resistance from the things themselves [1. P. 3839], as their meanings are being blurred, getting out of shape, turning into variables. One may say anything, without meeting the resistance of reality, which becomes "loose" due to the abundance of individual projects, imageries, narratives, spreading in the media and pretending, each in its own way, that they reflect pure facts [2. P. 14].

At present it's getting harder to deny the current state of things and struggle for the implementation of ideals as the current state of things and ideals become disputable. The linear logic of protest finds itself blocked by the information environment, where all pros and cons of any significant event coexist. The facts which can fall under criticism are called into question: whether a certain event has taken place and, if so, what its message is. Reality turns into a network of conversations, discussions, points of view. Any impulse of denial runs into the semantic uncertainty of the events, inevitably becomes overwhelmed with alternative interpretations, freezes in suspension without making a change, but instead - confirming the complexity of social life and the relativity of its explanations.

In the modern situation of simultaneous plural interpretations, social criticism focuses on the language of culture as such, and one of the main tasks of this activity is to differentiate discourses, semantic fields, linguistic practices which predetermine the vision of reality. In this case social criticism struggles not with the language or sign system, but, first of all, with the indifference of the majority towards meanings and implications, concealed or contained in the language of culture. The aim is to draw human attention back from the sign flow, where it is captured by images, words, information, to analytical activity revealing distinction between contexts, connotations, strategies of reasoning. An alternative to empty conversations is the interpretation perplexed by heterogeneity of the cultural field.

Within critical interpretation the reality appears as a multidimensional text, which nevertheless may not be perceived as a whole, from beginning to end, for it has no single author, completed structure, the core narrative thread or even one language. There are "small texts" and the analysis of them leads to several critical revelations: the power of sign, which is plastic and open by nature but in the shape of "the originally given" is incontestable; the power of discourse fighting with chaos of impressions, while disciplining and suppressing the human self-expressions; the power of quotations, which make one stay on repetition grounds while creating the effect of novelty. Revelations do not claim universality, they describe fragments of the cultural and historical experience, concentrate on the moments of creation and objectification of artifacts, primarily in the language of culture. The texts include popular best sellers, commercials, scientific paradigms and cultural practices built into the fabric of everyday life. The authors of semiotics (R. Barthes, U. Eco) develop a model of critical analysis that makes it possible to trace all aspects of social construction and establishment of symbolic systems with its linguistic mechanisms of putting questioning limits on readers, audience, listeners, authors, i.e. on those who live with many kinds of texts and takes part in creation thereof.

Treating the culture as multidimensional text in many respects resembles demythologization which opens up stable structures, repeated and alienating patterns, power and submission motives, behind a mass of endless conversations and entertaining stories. Meanwhile an interpreter conceives a text as a thing meant for thoughtful reading, an object that excludes incoherence, futility, semantic emptiness. To appreciate the text means to see a complicated formation with its own rules of the game, story line, rationality of action, the logic of change, repetitions, borrowings and findings, new combinations of known elements. Looking, for instance, at the well-known best seller by I. Fleming, devoted to J. Bond, U. Eco notes the use of elements of magic fairy tale, black-and-white perception of the world, demonstration of binary thinking, an application of a character-machine, 
finds the intersection of various quotations from classical works [3]. The same story line analysis, in fact, is done by R. Barthes, who considers the "deep" detergent commercial, flood news, ideas about Einstein brain etc. [4]. To distinguish the text means, first of all, to realize the variety of linguistic techniques, communicative actions that prompt people to accept and understand the "obvious"; it also means to identify the complex symbolic and psychological structures that underlie both the common formulas of everyday perspective and mass culture constructions.

On the one hand, critical reflection in general is opposed to the trends of simplified perception of reality in mass media [5], resists the practice of "naive reading" constrained by habitual associations and lack of investigative interest in the whole range of meanings. On the other hand, it has nothing to do with the practice of dramatic "revaluation of values", leading to the sense of deontologization of reality and regard of the social sphere as the sphere of "words only". The critic's position in this case is that of a "sophisticated reader" (U. Eco), who refrains from overreliance on the texts and does not feel total disappointment in the social as such. The "sophisticated reader" avoids both the power of language, which he makes the subject of descriptive analysis, and the power of reality itself, which he methodologically considers as the system of human knowledge.

Critical analysis does not only detect the power of language but also reveals its exuberance, demonstrating ingenuity and great deal of possibilities, hidden in texts ${ }^{1}$. The object of criticism is simultaneously the source of aesthetic pleasure and the proper milieu for the continued social study. A critic does not treat language as a user or consumer, who forgets what has been said or read as soon as desired information is obtained, being satisfied with the first impressions; on the contrary, a critical thinker constantly feels the presence of language element: ambiguous, changeable, full of possible traps, but yet provoking endless reflection on society, its history and human existence.

\section{THE SUBJECT OF CRITICAL INTERPRETATION AND EXPERIENCE OF LIMITED KNOWLEDGE}

A contemporary critic differs from others by his/her ability to feel confident in symbolic space of culture, understand the variety and uniqueness of discursive practices. Does it mean that a critic knows more than others? It does, if knowledge includes a linguistic competence, an ability to work with texts, not to be under the power of language, not to trust in statements and ideals taken for granted. A critic refrains from participation in communications based on habitual storage of knowledge in order to understand social construction of knowledge. This is an approach by $\mathrm{M}$. Foucault who studies a repressive function of rational discourses; a general approach by semiotics' authors who study mini-myths as verbal or visual "ready-made" structures disconnected from historical reality and real personal experience; a method of deconstruction by J. Derrida who

\footnotetext{
${ }^{1}$ As G. Hartmann puts it, "the real excitement in criticism is to find a certain waves, and wavelets within the wave, and how things move and move back - the entire weather-map of intellectual affairs" [6. P. 84].
}

analyses the elements of texts preceding any textual whole with its well-known meanings.

A critic interpreter is occupied with analytical activity, detailed description of sign reality which has nothing to do with any prophecy or protest inspired by grand values. The critique in this sense is unobtrusive and uses no bright declarations. Nevertheless it can't be identified with only scientific theoretical approach, initially determined by accepted standards of factual material processing. Critic's mind is non-paradigmatic, his/her activity resembles movement in a dark forest, in an unknown territory, without compass or map. ${ }^{2}$

The criticism of this kind is characterized by a careful handling with any kinds of knowledge, including the one a critic produces. A certain methodological skepticism prevents this kind of criticism from dogmatism that is manifested in unconscious unification of cultural phenomena reduction of a whole variety of modes of existence, selfexpression, perception of reality to a common denominator, formula, recipe. Unlike others critic doesn't know or, more precisely, he/she is aware of limits of one's own point of view. This "clever ignorance" presupposes the acknowledgement of conventionality of any established system of knowledge, an assumption that critical reflection is first of all a human activity with its drawbacks and that a privileged position of thinking is only a claim that, in its turn, needs critical examination. This is an experience of "open" thought which accepts the initial uncertainty and diversity of life and resists any final or absolute judgments [8].

A final point in the strict sense is impossible. Finalization immediately makes a critic an advocate of this or that school, direction, discourse. Nevertheless the striving for a point of view to expose the hidden meanings of texts or practices, to work out the uncertainty of social life at a rational level, to take a challenge of the "already known" without generating the ultimate answer are the elements of critical interpretation. A critic starts with the experience of limited knowledge and ends up with it or, to put it better, with a calm attitude towards results of one's own research. Some sort of ignorance in this case is neither perplexity, nor deficiency of knowledge but a symbol of thinking that never ceases to invent and unfold new perspectives of vision, just as the language of culture never stops producing new "traps" of consciousness, ideologies, myths.

Unsatisfied with the knowledge which provides a person with a certain place in society (as a specialist, a follower of this or that ideology, a representative of a certain culture), an interpreter prefers a position that isn't locked within any particular point of view, but implies a constant movement between established views, feeling freedom from typologies invented by others or created out of personal preferences ${ }^{3}$.

\footnotetext{
${ }^{2}$ In interview with S. Hasumi (1977) M. Foucault says that he has no ready- made instruments for his studies, they are born out of researching activity, out of the objects he opens up. That's why he has to "stumble along", "moving from one book to another" [7. P. 286-287].

3 As M. Walzer writes, "we can never be consistent defenders of multiculturalism or individualism; we can never be simply communitarians
} 
Everybody knows something that they take for an absolute knowledge, while an interpreter is attentive to the context or limited conditions of validity of the concrete system of knowledge. This "intellectual honesty" (K. Popper) enables $\mathrm{him} / \mathrm{her}$ to strive for understanding of what is going on, satisfying this demand through continuous analysis of symbolic formations and putting aside any holistic project of realizing grand and totally novel social constructions. A critic-interpreter does not act as "an exception from the rule" but treats any cultural text as an "exception" (a unique phenomenon) which is worthy to understand in historical context and beyond the socially recognized system of knowledge production, distribution and use.

\section{CRITICISM AND POST-UTOPIAN CONVERSATION WITH OTHERS}

An ideal social actor of a new model of social criticism is a person, who does not negate an incomprehensible phenomena of other cultures and does not simplify them by using familiar explicatory schemes taken for granted in his/her cultural world [8]. While traditional criticism begins with an experience of alienation, the contemporary critics begin with experience of understanding. Just as the experience of alienation forces an individual to speak not as everybody else, express an individual vision of the situation, the experience of understanding makes a person leave the common ground of mass media recipients. Just as the experience of alienation is inextricably linked with the sense of loneliness, the experience of understanding distances a person from the mass of people, immersed in their limited symbolic worlds. However unlike the experience of alienation, critical interpretation is tuned to uninterrupted exchange of ideas, opinions, sublimating any radical or revolutionary gesture into dynamic element of human conversations.

In traditional criticism the conversation introduces a new world, new forms of social interactions as a single goal that all other tasks should be subdued to. The problem concerns human capacity to pull one's energy together to achieve it. In contemporary criticism the conversation itself opens up a new range of possibilities, relieves participants from anonymity of social atoms, creates a space of understanding, everybody may become an interpreter, ready to learn a complicated art of listening to others, analyze statements, reconsider one's point of view on reasonable grounds. Though this space is limited in time, it keeps having an impact on human minds after the conversation is over.

Thus the social criticism as interpretation has its own high expectations concerning a social interaction. Traditional criticism is under the illusion that the conversation, the vehement, sharp word may become a weapon against inert reality, launch the process of bringing into life the ideals proclaimed. Contemporary criticism implies that during a certain conversation a special communicative space, coming out of daily routine, is made up. Modern "post-utopian" thinking trusts in conversation, which both liberates human

or liberals, or modernists or postmodernists, but must be now one, now the other, as the balance requires" [9]. beings intellectually and by no means can lead to aggression, the affront to human dignity, suppression of creative abilities. To be able to criticize means to be careful in rejecting human faults and be ready to do honour to any individual or cultural achievement, to notice opportunities for positive changes, help others see these opportunities as well: "And we must think of criticism not as an offense, or as a show of contempt or disdain, but as one of the greatest signs of respect that one mind can show to another" [10. P.48].

A new man of contemporary social criticism should be able to talk - on his own behalf (avoiding the popular schemes of explanations) and listening to others (avoiding the egocentric attitude). The presumption of meaning inherent in other points of view, intellectual honesty and inclination to explain one's own position to others and to oneself [11. P. 297], openness to new facts and situations is the key features of an ideal critical conversation that challenges to traditional thinking with its trust in absolutes and the only correct position of an objective observer. To be able to criticize means to be able to understand other human beings in their specific situations and social contexts.

Utopian intentions distinguished by their mobilizing energy to reach an ideal social state or conditions, are substituted by the conversation intended to reach a special "speech situation" (J. Habermas) that overcomes hypnotic effects of mass culture and authoritative influence of the social system. This conversation is supposed to untie participants from the predetermined role-playing relationship, from alienated or relaxed state of mind, oversaturated by the over-flowing "pictures of reality", from a habit of perceiving one's own life automatically as something positive or negative, something guaranteed and requiring no adjustments. "Speech situation", created in the course of critical interpretation, is ideal in the sense that personal rational resources are not suppressed and serve to no power interest as far as the social interaction is concerned. This is a conversation where there is enough time to appreciate the Other's thoughts, desires, insights, as well as to reconsider one's own life.

\section{CONCLUSION}

Post-utopian thought has no illusions about the final transformation of consciousness and human relations. Interpretation is the process partially revealing meanings (which is locked in the customary language of culture) and temporarily releasing the consciousness from the ideology and stereotype pressure (due to analytical activities of critics dealing with texts). Understanding has the beginning and the end in time; it is provoked by this or that situation, text, existential human needs. Understanding is discrete, but simultaneously this discreteness ensures a perspective to resume the critical conversation/interpretation any time. It is the main task which basically can't be completed by any person without losing the elementary curiosity, sensitive attitude to different lifestyles and standards of communal life. And this job of understanding is not for one, but for many: "It is better to tell stories, better even though there is no definitive and best story - better even though there is no 
last story that, once told, would leave all future storytellers without employment" [8. P.65].

\section{REFERENCES}

[1] Walzer M. The Company of Critics: Social Criticism and Political Commitment in the Twentieth Century. Translated from English. M.: Ideya-Press, Dom intellectualnoy knigi, 1999. 360 p.

[2] Vattimo G. The Transparent Society. Translated from Italian by D. Novikov. - M.: Logos, 2002. 128 p.

[3] Eco U. The Role of the Reader. Explorations in the Semiotics of Texts. - Bloomington and London: Indiana University Press, 1979. $288 \mathrm{p}$.

[4] Barthes R. Mythologies. Translated from French by S.Zenkin. - M.: Izdatelstvo im. Sabashnikovyh, 2000. 320 p.

[5] Chistyakova O. Human in a Mediatizing Postmodern World: Anthropological Meanings and Social Implications // Human. Society. Inclusion. N 2-1 (26), 2016. pp. 90-98.

[6] Criticism in Society: Interviews with Jacques Derrida, Northrop Frye, Harold Bloom, Geoffrey Hartman, Frank Kermode, Eduard Said, Barbara Johnson, Frank Lentricchia, J. Hillis Miller by Imre Salusinszky. - N.Y., L.: Methuen, 1987.

[7] Foucault M. Intellectuals and Power: Selected Political Articles, Speeches, Interviews. V.1. (1970-1984). Translated from French by S.Ch. Ofertas. - M.: Praxis, 2002. 384 p.

[8] Walzer M. Interpretation and Social Criticism. Cambridge: Harvard University Press, 1987. 96 p.

[9] Walzer M. On Toleration. Kindle Edition.- Yale University Press, 1999. $148 \mathrm{p}$.

[10] Notturno M. A. The Open Society and Its Enemies: authority, community and bureaucracy. // Popper's Open Society after 50 years. Eds. by I. Jarvie and S. Pralong - L. and N.Y.: Routledge, 1999. pp. 42-56.

[11] Benhabib S. Critique, Norm and Utopia: A Study of the Foundation of Critical Theory. - N.Y.: Columbia University Press, 1986. 455 p. 